Article

\title{
Cookie-Jar Alarms: An Analysis of First-Grade Students' Gendered Conceptions of Engineers following a Programming Design Task
}

\author{
April Mitchell, Kimberly H. Lott * and Colby Tofel-Grehl
}

check for

updates

Citation: Mitchell, A.; Lott, K.H. Tofel-Grehl, C. Cookie-Jar Alarms: An Analysis of First-Grade Students' Gendered Conceptions of Engineers following a Programming Design Task. Educ. Sci. 2022, 12, 110 https://doi.org/10.3390/ educsci12020110

Academic Editor: João Piedade Received: 16 December 2021 Accepted: 24 January 2022 Published: 7 February 2022

Publisher's Note: MDPI stays neutral with regard to jurisdictional claims in published maps and institutional affiliations.

Copyright: (C) 2022 by the authors. Licensee MDPI, Basel, Switzerland. This article is an open access article distributed under the terms and conditions of the Creative Commons Attribution (CC BY) license (https:// creativecommons.org/licenses/by/ $4.0 /)$.
School of Teacher Education and Leadership, Utah State University, Logan, UT 84322, USA; april.mitchell@aggiemail.usu.edu (A.M.); colby.tg@usu.edu (C.T.-G.)

* Correspondence: kimberly.lott@usu.edu

\begin{abstract}
Women remain underrepresented in engineering and broadening participation has recently become the focus of education reform efforts. Increased emphasis on $\mathrm{K}-12$ engineering education calls for the design of learning environments and curricula that increase interest and conceptual understanding of engineering work, beginning in the early years of childhood. We seek to understand what works, for whom, in what contexts, how it works, and how engineering curricula can be improved to promote social justice. Here, we evaluate the impact of a curricular intervention designed to promote equity in elementary engineering education. The integrated STEM curriculum unit engages first-grade students in programming a cookie-jar alarm. Using a KIBO robot, students program a distance sensor to trigger the alarm and customize the sounds and flashing lights. Students' pre-/post-drawings of 'engineers at work' were used to elicit reflection in semi-structured interviews, and to assess changes in students' conceptions of engineering work following the curricular intervention. A mixed analysis of the data revealed students' conceptual understanding of engineering work improved following the two-week curricular intervention, regardless of gender. However, the girls in the study were more likely than boys to identify as an engineer following the programming design task. We discuss the students' self-reported explanations and elements of the intervention that may have facilitated conceptual change. We recommend that, to promote equity in engineering education, "gender-responsive" curricula are essential.
\end{abstract}

Keywords: early childhood; engineering; robotics; STEM; gender differences

\section{Introduction}

Broadening participation in engineering to underrepresented groups is an important global priority and has recently become the focus of education reform efforts. In the United States, recommendations for engineering education published in A Framework for K-12 Science Education (NRC, 2012) have been incorporated into standards that specifically address engineering practices and core ideas of the discipline (NGSS Lead States, 2013). This shift toward K-12 science and engineering education requires the development of new curricula [1,2], teacher professional learning, and the expansion of research efforts to identify developmentally appropriate and culturally relevant pedagogy [3-6]. The profession of engineering is heavily affected by a gender gap, with females comprising only $10-20 \%$ of engineering undergraduates and professionals [7]. Gender disparities with regard to student knowledge and interest in engineering have been documented as early as age 10 [8]; thus, early intervention is critical for promoting equity in engineering education [9]. Early research on students' conceptions of engineers has shown that elementary students [10,11], as well as middle-school students $[12,13]$ are largely unaware of engineers and have misconceptions about the work of engineers.

In this study, we use feminist critical theory to explore how children's conceptions of engineers are culturally constructed in ways that disadvantage girls, and identify factors 
that mediate conceptual change. The research question we address is: How does a genderneutral programming design task influence first-grade students' conceptions of engineers and/or interest in engineering? Our conjecture is that boys and girls respond differently to the same engineering curriculum and that students' identity work can be influenced by the context of the study. Currently, many engineering curricula [14-16] engage students in competitions to design a vehicle (e.g., car, rocket) or large structure (e.g., bridge, tower), often thought of as "boy stuff". A cookie-jar alarm was chosen as the design task for this study because it was more gender-neutral. That is, we intentionally designed the curriculum to promote interest in engineering for all students, but especially for girls. Using a mixed-methods approach in which students' pre-/post-drawings of 'engineers at work' were used to prompt reflection in semi-structured interviews $(n=15)$, we assessed changes in students' conceptions of engineering work following the curricular intervention. Based on a mixed analysis of the data, we provide preliminary evidence that the curricular intervention differentially influenced students' interest and engineering identity based on gender. Following the curricular intervention, significantly more girls than boys responded in the affirmative when asked, "Do you think you are an engineer?" $(p=0.041)$. We conclude with a discussion of students' self-reported explanations, and elements of the intervention that may have facilitated conceptual change. The preliminary findings will be useful to researchers interested in designing "gender-responsive" learning environments and engineering curricula that better support girls' identity work in STEM.

\section{Literature Review}

To better understand how the discipline of engineering could be conceptualized by young children, we review the research literature on the nature of engineering, young children's (mis)conceptions of engineering, and the affordances of integrating engineering and technology into a reform-based science curriculum for elementary students.

\subsection{Nature of Engineering}

The authors of $A$ Framework for K-12 Science Education (NRC, 2012) define engineering as "a systematic and often iterative approach to designing objects, processes, and systems to meet human needs and wants" (p. 202). They recommend students engage in the engineering-specific practices of defining problems and designing solutions. Scholars have since argued for a greater distinction between science and engineering as separate disciplines and an extended list of engineering practices, including envisioning multiple solutions, making trade-offs between criteria and constraints, investigating properties and uses of materials, learning from failure, and working effectively in teams, to name a few $[17,18]$. Based on the Nature of Science (NOS) literature, other scholars have suggested we refrain from developing an unproductive list of NOE tenets to be learned and assessed, offering instead a set of questions to prompt student discussion [2]. Pleasants and Olson, for example, envision engineering education to include discussions on "what engineering is, how it works, how engineers conduct their work, the relationship between engineering and other fields of study such as science, and how engineering influences and is influenced by society" (p. 146).

Based on empirical work with elementary students, Capobianco, Diefes-Dux, Mena, and Weller [10] offer a practical list of 'attributes of engineers' that can be taught to young children: an engineer is someone who is creative, works in teams, uses science, mathematics \& technology, designs everything around us, and solves problems to help people. The authors argue that this framework "allows students to identify with one or more attributes and potentially build interest, confidence, and participation in engineering by envisioning themselves as possessing and/or practicing these particular attributes" (p. 321). We adopted this framework as the target conception of engineers for our current study. 


\subsection{Students' Conceptions of Engineering}

When students in elementary school $[10,11]$ or middle school $[12,13]$ are invited to draw an 'engineer at work', they typically draw a male engaged in the work of driving a train, fixing a car, or building a house. Thus, students typically conflate professional engineers with skilled laborers and fail to recognize engineers as designers. For over a decade, a simple but effective instrument known as the Draw an Engineer Test (DAET) [19], a variation of the more traditional Draw a Scientist Test [20], has been used to assess students' (mis)conceptions of engineers. Students' drawings, when combined with open-ended writing prompts, have been quite useful for uncovering stereotypes held by students about engineers. Recently, a modified version of the Draw an Engineer Test [21] was used with teachers in a pre-/post research design [22]. Researchers uncovered that the elementary teachers in the study $(n=30)$ held many of the same misconceptions as students, but the teachers' conceptions of engineers expanded following participation in summer professional development $(p=0.001)$. The authors of the DAET suggest the instrument could also be used in pre/post research designs to document changes in students' conceptions over time, although this has yet to be demonstrated. The current study hopes to make a contribution here.

Notably, drawings of an engineer at work do not necessarily assess an individual's knowledge of engineering, interest in engineering, or confidence in engineering (i.e., selfefficacy). Thus, researchers have begun to develop other Likert-type survey instruments for this purpose, such as the Engineering Identity Development Survey (EIDS) [23,24], the Engineering Interest and Attitudes (EIA) survey [25], and the Knowledge of Occupational Activities Measure-Engineers (KOAM-E) [9]. Interestingly, the latter was used to assess differences in engineering knowledge and interest levels among Caucasian $(n=152)$ and Latinx students $(n=167)$ in grades K-5. The authors found a correlation between knowledge and interest levels, with Caucasian students showing more interest and significantly higher levels of engineering knowledge than Latinx students. This underscores the importance of early intervention to promote equity in engineering education.

\subsection{Effects of Engineering Curriculum}

The development of K-12 engineering curricula began in earnest in the 1990s, although research on the effectiveness of such interventions is still limited [26]. One notable example is an evaluation of selected lessons from the elementary curriculum program, Engineering Is Elementary [27]. Using a pre-/post quasi-experimental research design, researchers showed that the implementation of at least one Engineering Is Elementary lesson in grades 2-4 significantly increased students' knowledge of engineering $(n=741)$ compared to a control group $(n=90)$. Average scores for the treatment group ranged from $58-66 \%$ on the post-test, with growth scores between $22-29 \%$. Participants in grades $2-4$ also showed significant gains in engineering identity development relative to the control group, as measured by the previously validated instrument Engineering Identity Development of Students (EIDS) with no significant differences observed based on gender [23,28].

Similarly, a randomized controlled trial $(n=14,015)$ across three Eastern states was conducted to assess student achievement in grades 3-5 following lessons from Engineering is Elementary (EiE) compared to a more "traditional" engineering curriculum that addressed the same content [29]. Details about how the EiE pedagogical approach differs from traditional engineering curricula had been described previously [30]. Using a multilevel regression analysis with nested data, researchers found participation in the EiE curriculum was a significant predictor of students' engineering and science content knowledge. An important factor mediating student learning was the pedagogical approach, with students benefiting more from active learning and discussions than passive learning and didactic teaching. That said, the quality of students' writing in their engineering notebooks was higher in the comparison group [31]. Interestingly, females had larger learning gains than males in engineering, but not on the science assessment in both the treatment and comparison group. The study also found that interest in engineering declined in older 
students as they moved from grade 3 to 5 . The authors argue that early intervention is key to developing an engineering identity.

Researchers have begun to explore the benefits of integrating technology into elementary STEM curricula, particularly engaging students in design tasks that involve programming. Impressively, young children ages 4-7 were shown to be capable of building and programming $\mathrm{KIBO}$ robots [32], snapping together wooden blocks to program a sequence of steps for the robot to follow. The KIBO robots can move, light up, make sounds, and respond to stimuli in the environment using a variety of sensors. The researchers subsequently measured gains in K-2 students' programming skills, as well as engineering interest and attitudes, before and after a Helpful Robots curricular intervention [33]. They found that, while boys expressed a significantly greater interest in engineering on the presurvey, girls and boys $(n=105)$ were equally interested in engineering on the post-survey. That is, using a valid and reliable instrument with a pictorial Likert-like scale [26], K-2 girls were more likely to agree with the statement, "I would enjoy being an engineer when I grow up". Girls in the control group did not show significant growth in attitudes about engineering, suggesting that the observed increase in engineering interest was a direct result of the robotics curriculum. The authors attribute the success of the Helpful Robots curriculum to its focus on care rather than competition, an approach thought to promote equity and girls' participation in engineering $[34,35]$. However, a limitation of the study is that researchers did not assess students' (mis)conceptions of engineers, which likely influenced their responses on the pre/post engineering attitudes assessment.

We seek to complement these large-scale quantitative studies with a rich description of how and why the experience of participating in an engineering design task can change students' conceptions of engineers and/or influence students' engineering identity. Our conjecture is that boys and girls may respond differently to the same engineering curriculum and that students' identity work can be influenced by the context of the study. Thus, we designed a curriculum to promote interest in engineering for all students, but especially for girls. Using students' pre-/post-drawings to elicit students' ideas, we specifically asked students in semi-structured interviews to explain what it was that had changed their thinking about engineers following the curricular intervention. Here, we report the effects of the cookie-jar alarm design task on students' conceptions of engineering. Based on a mixed analysis of the data, we provide preliminary evidence that the curriculum differentially influenced students' interest and engineering identity based on gender.

\section{Methodology}

We used a sequential transformative mixed-methods research design [36] to investigate students' gendered conceptions of engineers and interest in engineering before and after a curricular intervention. A transformative design was appropriate here because the purpose of the project was to benefit a marginalized group (girls) and identify new ways to bring about social change [37-39]. The sequential mixed-methods research design (QUAN $\rightarrow$ QUAL) allowed us to document inequity quantitatively, then explore the cause of the inequity qualitatively by interviewing participants about their experiences. The study concludes with an integration of the QUAN and QUAL data to analyze the relative effectiveness of the curricular intervention for girls compared to boys. Specifically, we work towards the development of a theory grounded in the data (MM-GT) to explain why girls and boys might respond differently to the same engineering curriculum [40-42]. We seek to answer complex, process-oriented questions: What works, for whom, in what contexts, how does it work, and how can conditions be improved to promote social justice?

\subsection{Theoretical Framework}

The data collected in this study are interpreted using the lens of feminist critical theory [43]. Feminist theory seeks to explain the imbalance of power between men and women in society and the factors that shape or shift a woman's identity [44-48]. Social, economic, and political systems that disadvantage women or position women as second to 
men in society can be attributed to the deep rootedness of patriarchy. Stacey [43] explains, "the valuing of the male over the female... [is] something we all internalize, not simply as a conscious belief we have been socialized to accept, but in the formation of our earliest sexual identities which take place through unconscious as well as conscious processes" (p. 58). Feminist scholars seek to dismantle systems of oppression through consciousness raising, the problematization of ideas, and collective activism, creating more equitable relations for all people-both men and women [49]. Scholars have contributed to our understanding of how to achieve gender equality across various social and cultural contexts, including STEM education [50,51].

As early as age 10, students begin to associate engineering with masculinity [8]; thus, early intervention is critical for promoting equity in engineering education [9]. How might the patriarchal narrative of what it means to participate in engineering be disrupted to broaden girls' participation? Here, we apply feminist critical theory to interpret qualitative data from student interviews in early childhood classrooms, giving special attention to how the word 'engineer' or 'engineering' is given meaning in a way that excludes girls from participation during the formation of their earliest identities. Our work is informed by previous feminist scholars who have provided analytical tools for theorizing girls' / women's lived experiences in the male-dominated fields of science and engineering [52-55].

\subsection{Participants}

An experienced first-grade teacher was recruited to participate and enact the curricular intervention for this study. It was her first time using the KIBO robotics kits. Of the 25 students in her classroom, 15 students consented to participate in the follow-up interviews, including 8 girls and 7 boys. The first-grade classroom was situated in a laboratory school located on a university campus in the Western United States, with a student population that is $85 \%$ White, $7 \%$ Hispanic, and $8 \%$ other races/ethnicities. The majority of students who participated in this pilot study were White (93\%). Approximately $22 \%$ of students qualified for free or reduced-price lunch.

\subsection{Curricular Intervention}

The integrated STEM curriculum unit was designed by the authors [56] to align with first-grade Next Generation Science Standards about light and sound (NGSS, 2013). The cookie-jar alarm design task was inspired by a recent innovation in educational technology, the KIBO robot $[32,33]$. The robot can be programmed by young children ages $4-7$, without the use of a computer, by sequencing and scanning tangible wooden blocks. Wheels, motors, electric outputs (light and sound), and a variety of sensors allow children to customize their robot in a way that is personally meaningful to them, and to engineer a robot that is useful for solving a problem.

We chose the cookie-jar alarm for this study because it is a relatively gender-neutral project compared to other common design tasks observed in elementary classrooms, such as bridges, houses, vehicles, rockets and the like. Students were able to program the robot, using a distance sensor to trigger an alarm and customize the sounds and flashing lights. With the help of the classroom teacher literacy strategies were also incorporated into the unit [57], including a reading of the book, Who Took the Cookies from the Cookie Jar? (Lass \& Sturges, 2000), and the writing of a basic algorithm (a sequence of steps for the robot to follow). The two-week unit engaged the children in every step of the engineering design process. First, students defined the problem as presented in the storybook, discussed the ways light and sound can be used to communicate, and sketched a design plan for a cookie-jar alarm [58]. Second, students worked in collaborative groups to assemble needed parts of the KIBO robot and sequence the wooden blocks to develop a program. Third, students optimized the design solution based on iterative testing, ultimately acting out the storybook problem to ensure the alarm could effectively warn others. Finally, students were invited to describe their alarm system to their peers and justify their design 
decisions [59]. Reflections on the engineering design process in whole-group discussions occurred throughout the unit [60].

\subsection{Data Collection}

To document inequity and make visible students' gendered conceptions of engineers, we used a previously developed instrument known as the Draw an Engineer Test [19,21]. Students were invited to create a pre-/post-drawing of an 'engineer at work', then write a sentence to describe what he (or she) was doing.

To better understand how and why students' conceptions of engineering might change, we conducted semi-structured interviews with students $(n=15)$ following the curricular intervention. We elicited students' thoughts and lived experiences as they examined their pre-/post-drawings from the Draw an Engineer Test. We concluded the interview by asking students: Do you think you are an engineer? Why, or Why not? The purpose of this final question was to assess students' interest and attitudes toward engineering. The complete interview protocol is found in Appendix A.

\subsection{Data Analysis}

Data from the Draw an Engineer Test was quantitatively analyzed by conducting Fisher's exact test to determine whether differences between students' drawings were statistically significant. Specifically, we tallied the frequency in which students chose to draw a male or female engineer and counted how often certain objects and actions were included or described in the drawings.

Interview transcripts were coded using a grounded theory approach (MM-GT) for the purpose of developing a model that explains how or why boys and girls might respond differently to the same engineering curriculum [40-42]. Constant comparative methods with iterative coding and analysis were employed. That is, open, axial, and selective coding were sequentially used by the first author to identify how and why the cookie-jar alarm intervention may (or may not) have facilitated conceptual change and increased interest in engineering among first-grade students based on gender. Open coding involved reading students' interview transcripts carefully (alongside their pre-/post-drawings of an engineer), capturing reflective memos in the margins, and organizing significant statements into a table. The result was a list of pivotal ideas that had changed students' conceptions of engineers or increased students' interest in engineering. During axial coding, interview transcripts were reread and memos expanded to highlight similarities and differences based on gender, or the lived experiences of the boys compared to the girls. Finally, selective coding was used to examine the relationship between pivotal ideas and the affordances of the curricular intervention (i.e., the contextual and intervening conditions).

To evaluate the relative effectiveness of the intervention for boys compared to girls, the quantitative data from the Draw an Engineer Test and the qualitative interview data were integrated to evaluate students' conceptual understanding of engineering work before and after the cookie-jar alarm design task. Using a previously developed rubric [21,61], students' mental models of engineering were categorized along a three-level continuum. The differences among the levels described in the rubric are as follows: Level 0 represents a naive conception of engineers (e.g., engineers make statues), Level 1 represents a limited or alternative conception of engineering (e.g., engineers drive trains or fix cars), Level 2 represents a basic understanding of engineering (e.g., engineers design), and Level 3 represents a more advanced understanding of engineering (e.g., engineers design for a purpose). A paired Wilcoxon signed-rank test for nonparametric data was used to analyze the differences between pre/post ranks and assess growth in students' conceptions of engineering. The Mann-Whitney $U$ Test for nonparametric data was used to compare differences between boys and girls on the post-assessment and to evaluate the relative effectiveness of the curriculum for the two groups. A Shapiro-Wilk test showed that the data were not normally distributed. However, both the Wilcoxon signed-rank test and the Mann-Whitney $U$ test do not require a normal distribution. 
Finally, we analyzed students' responses to the survey question, "Do you think you are an engineer?" Possible responses were Yes, Maybe, or No. We compared differences in students' responses based on gender using Fisher's exact test. We also analyzed the relationship between engineering identity and knowledge of engineering work by calculating the Spearman's rho correlation coefficient.

\section{Results}

To understand how students' conceptions of engineers and the work of engineers changed following the curricular intervention, we quantitatively analyzed students' preand post-drawings from the Draw an Engineer Test (DAET). We found the majority of students $(67 \%)$ conceptualized engineers as male in the pre-drawings, including all the boys $(100 \%)$ and almost half of the girls $(37.5 \%)$, providing evidence that gendered conceptions of engineers were already present among the first-grade students in this study. However, following the two-week curriculum intervention all eight of the girls drew female engineers in their post-drawings (Table 1).

Table 1. Changes in students' conceptions of engineers from the pre-/post-DAET.

\begin{tabular}{cccccccc}
\hline & \multicolumn{3}{c}{ Preconceptions } & \multicolumn{3}{c}{ Post-Conceptions } & \\
\cline { 2 - 7 } & $\begin{array}{c}\text { Male } \\
n=7\end{array}$ & $\begin{array}{c}\text { Female } \\
\boldsymbol{n}=\mathbf{8}\end{array}$ & $\begin{array}{c}\text { Total } \\
\boldsymbol{n}=\mathbf{1 5}\end{array}$ & $\begin{array}{c}\text { Male } \\
\boldsymbol{n}=\mathbf{7}\end{array}$ & $\begin{array}{c}\text { Female } \\
\boldsymbol{n}=\mathbf{8}\end{array}$ & $\begin{array}{c}\text { Total } \\
\boldsymbol{n}=\mathbf{1 5}\end{array}$ & $\begin{array}{c}\text { Pre/Post } \\
\text { Comparison } \\
\boldsymbol{n}=\mathbf{1 5}\end{array}$ \\
\hline $\begin{array}{c}\text { Engineers Are } \\
\text { Male }\end{array}$ & 7 & 3 & 10 & 7 & 0 & 7 & $p=0.462$ \\
\hline $\begin{array}{c}\text { Engineers Use } \\
\text { Technology } \\
\text { (Robots) }\end{array}$ & 0 & 5 & 5 & 2 & 6 & 8 & \\
\hline
\end{tabular}

To understand students' conceptions of the work of engineers, we examined the objects that students included in the DAET and the action words that students used to describe the work of engineers. The most common object in the pre-drawings was a vehicle (47\%), such as a car or train, while the most common object included in the post-drawings was a robot $(53 \%)$. Interestingly, six of the eight students $(75 \%)$ who included a robot in the postsurvey were girls. Boys were more likely to include a vehicle in their post-drawing ( 3 of 7 , $43 \%$ ). Other objects in students' pre-/post-drawings included houses, a bridge, a rocket, a backpack, and a candy machine. On the post-DAET, the most common action word written to describe the work of engineers was 'fixing' (7 of 15,47\%), followed by 'making' ( 3 of 15, 20\%) and 'building' (2 of 15, 13\%). When interviewed, however, students used additional action words (e.g., inventing, creating, testing). Notably, interviews revealed that multiple students seemed to conflate the action word 'fixing' with the engineering practice of 'testing' (i.e., optimizing a design solution).

\subsection{Changing Gendered Conceptions of Engineers}

To explain how or why some students changed their conception of engineers and engineering work, we turn to a qualitative analysis of students' interview transcripts. Three girls in this study first conceptualized engineers as male in the pre-drawing but drew a female in the post-drawing. Here, we describe the explanations offered by the three girls (Girl 3, Girl 6, and Girl 8) as to why their thinking changed about who can be an engineer.

Girl 3 drew a boy building a rocket in the pre-drawing. Her dad, it turned out, was a "space engineer". Following the curricular intervention using KIBO, she drew a girl building a robot (Table 2). When the interviewer asked the girl about what inspired the changes in her drawing, her response was informative. 
Table 2. Pre/post drawings and student interviews provide evidence of conceptual change about who can be an engineer.

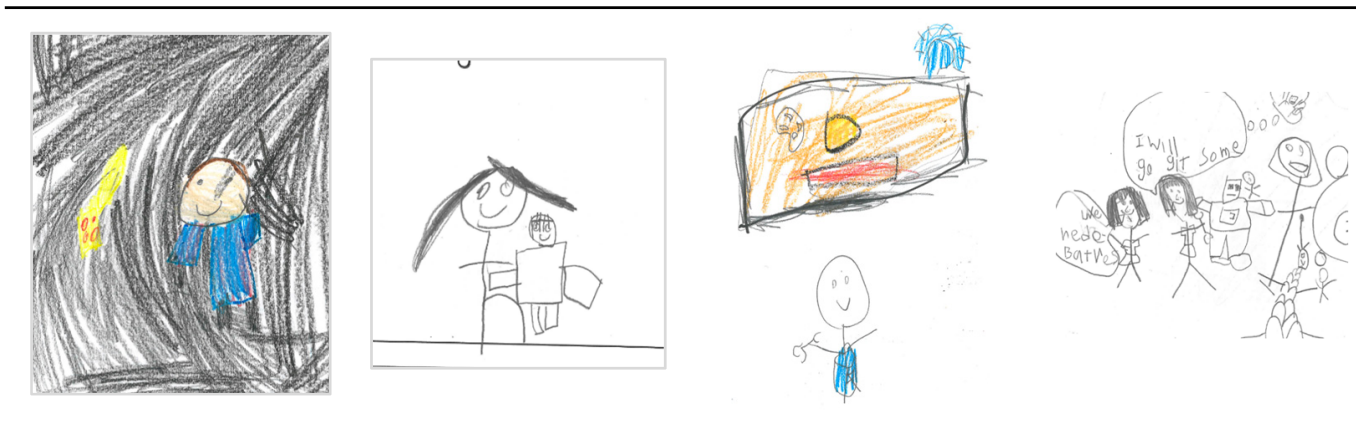

\section{Girl 3}

Pre-drawing: "My dad is building a rocket." Post-drawing: "They're building a robot." Why the change: "Because there's a lot of kinds of engineers."
Pre-drawing: "That is the car that he's fixing." Post-drawing: "There's two engineer partners $\ldots$ and they work together. They're building a robot and their mom's saying, "No, stop! You're making a mess!"

Why the change: "Because I wanted to kind of take turns."
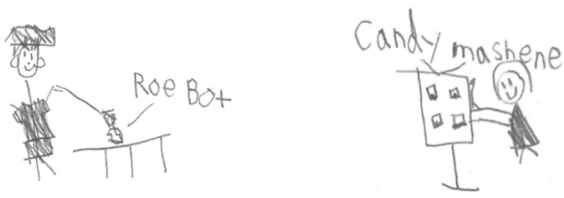

\section{Girl 8}

Pre-drawing: "I drawed a robot that they were building."

Post-drawing: "I'm testing it ... You just twist something and then candy falls out."

Why the change: "It's really interesting how it works."

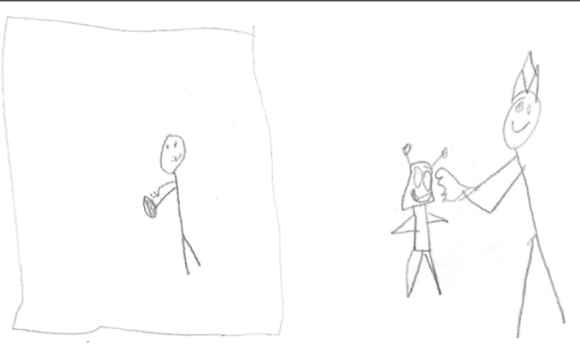

Interviewer: When you drew your first picture, which is right here ... can you tell me about that? Can you tell me about that person and what they're doing?

Girl 3: My dad is building a rocket.

Interviewer: Oh, okay. So it's your dad.

Girl 3: And a satellite...

Interviewer: Okay ... So then after ... you drew this picture. Can you tell me about what that person's doing?

Girl 3: They're building a robot.

Interviewer: Okay, so they're building a robot. Is that person a boy or a girl?

Girl 3: A girl.

Interviewer: Okay. Do you think you are an engineer?

Girl 3: Yeah.

Interviewer: Why do you think that?

Girl 3: Because my dad teaches me a lot about it.

Interviewer: Oh, really? What does he teach you?

Girl 3: My dad teaches me what satellites do, and how to make electrical stuff.

Interviewer: Okay, all right. Very good. So my last question is, this is what you drew, your dad, beforehand. And your drawing is different afterwards. So what do you think made you change your idea about engineers? 
Girl 3: Because there's a lot of kinds of engineers.

Interviewer: Okay. So maybe you realized that there are more kinds of engineers than just space engineers?

Girl 3: Yeah.

Perhaps not surprisingly, Girl 3 demonstrates quite an advanced conception of engineering. Her father is an engineer who designs rockets and satellites. Her dad teaches her about how things work and provides opportunities for her to "make electrical stuff". Yet, participating in the cookie-jar alarm design task still seems to have broadened her thinking about engineers. She now understands there are "a lot of kinds of engineers". She reports this newfound understanding expanded her thinking about engineers, changing her conception perhaps from engineer as her father (male), to the possibility of becoming a (female) engineer herself.

Moving to the next student, Girl 6 drew a boy fixing a car in the pre-drawing. However, in the post-drawing she drew two girls working together to build a robot (Table 2). The drawing reveals growth in her understanding of the social nature of engineering, and her interview suggests collaboration (rather than competition) is an element that attracts her to engineering. Interestingly, the interview raises a subtle but complex issue as Girl 6 describes the behavior of her mother in the drawing.

Interviewer: So, what can you tell me about the person in this drawing and what they're doing?

Girl 6: That's the person with the engineer tool ... and that is the car that he's fixing. Interviewer: Okay. Okay ... So, tell me about this engineer.

Girl 6: There's two engineer partners ... and they work together. They're building a robot and their mom's saying, "No, stop! You're making a mess!"

Interviewer: ... Can you tell me more about them?

Girl 6: ... They're twins and they want to be engineer buddies, and everybody needs a buddy.

Interviewer: For sure. Are they boys or girls?

Girl 6: Girls.

Interviewer: In one picture, your engineer is a boy, and in this picture, there's two engineers and they're girls.

Girl 6: Because I wanted to kind of take turns.

Interviewer: You wanted to take turns. That's a great way to do it. And do you think you're an engineer?

Girl 6: I don't really know how to build robots.

We find it compelling that Girl 6 drew a mother looming over the two girl engineers and their robots, criticizing them for "making a mess" and telling them to stop. Using the lens of feminist critical theory, we infer this student associates engineering with messy work that is not appropriate or even discouraged for girls. Further, the mother seems uninterested in the girls' work. This comes in sharp contrast to the ways fathers were typically portrayed by students in this study, as role models who fix and build and teach and don't seem to worry too much about "making a mess". This raises the question, what is the effect of having only male role models of engineers? How might girls' conceptions change if mothers, too, were (more often) engineers, or if mothers accepted/encouraged their daughters' interest in engineering?

Interestingly, while this student did expand her thinking about the work of engineers following the curricular intervention (from a male fixing a car to two females working together to build a robot), she still does not see herself as an engineer. Her response of, "I don't really know how to build", serves as a reminder that drawing a female engineer in this assessment is not necessarily an indicator of increased self-efficacy.

Finally, Girl 8 drew a boy fixing a robot and, later, a girl (herself) fixing a candy machine (Table 2). The interview uncovered that Girl 8 had quite a nuanced understanding of engineering, more than was revealed based on her drawing and written description alone. That is, although Girl 8 wrote the word 'fixing' on the post-drawing, she used the 
word 'testing' in the interview, explaining that engineering involves testing things to figure out how they work. Perhaps young children conflate the meanings of 'fixing' and 'testing' in the context of engineering. Regardless, the interview reveals Girl 8 has a deep interest in figuring out how things work.

Interviewer: When she [Mrs. C] asked you to draw an engineer ... this is what you drew ... Why did you draw that?

Girl 8: Because engineers fix robotic things like cars and stuff, so I drawed a robot that they were building.

Interviewer: Why did you think engineers fix robots?

Girl 8: They fix because like KIBO we did that, so if we messed up on KIBO we fixed it and we figured it out.

Interviewer: So, tell me about this person fixing the robot. Is it a boy or a girl?

Girl 8: A boy.

Interviewer: Okay, so let's look at your picture that you drew afterwards ... This one is fixing a candy machine.

Girl 8: I'm testing it.

Interviewer: Oh, okay. So, you're testing the candy machine. All right. So, what can you tell me about this engineer? Is it a boy or a girl?

Girl 8: A girl.

Interviewer: It's a girl. Okay ... What made you change your mind about engineers?

Girl 8: Well, I just thought about, like, how everything you just twist something and then candy falls out and it's really interesting how it works.

Interviewer: Oh, okay. So, the way the candy machine works was interesting to you. Girl 8: Mm-hmm (affirmative).

Interviewer: So, do you think you're an engineer? Yes? You're nodding yes. So, what makes you say that?

Girl 8: Because sometimes I like to change batteries in a watch ... or a toy that I have. And I like to play with robots, like, I have a robot ... that used to be my brother's ... and I have other little toys that can, like, talk.

Looking through the lens of feminist critical theory, it becomes significant that Girl 8 mentions playing with her brother's toys. Perhaps the boy with the robot in her pre-drawing is her brother. Her story begs the question, who decides which toys are appropriate for boys as opposed to girls? Do girls have access to their brother's toys? How might the kinds of toys available to girls (or deemed appropriate for girls) influence their conceptions of engineers and the designed world?

None of the boys in this study drew a female engineer, although Boy 1 spoke of a female engineer in the interview. He described having seen his mother fix her car before. Interestingly, the boy drew an engineer fixing a car in the pre-drawing and an engineer fixing a robot in the post-drawing, indicating a change in conception about the work of engineers (Table 2). His thoughts on why he changed his mind in the second drawing were insightful.

Interviewer: All right. So, here's what you drew before, and here's what you drew after. Is there anything that happened that made you change your mind ... what made you change your mind about engineers?

Boy 1: Because I thought he would be working on a bigger thing and he would be working on not a smaller thing.

Boy 1 revealed that what changed his conception of engineering work was the curricular intervention, which involved "a smaller thing", a robot programmed to be a cookie-jar alarm, and not a "bigger thing" like a car (or a train or a tall building or a bridge).

Taken together, the drawings and interviews with Boy 1 and the three female students, who originally drew boys in the Draw an Engineer Test, provide preliminary evidence that certain ideas are foundational to changing students' (gendered) conceptions of who can be an engineer: "there's a lot of kinds of engineers", engineers collaborate with "engineer 
buddies", engineering is "really interesting how [stuff] works", and engineers can work on "smaller thing[s]" not just "bigger thing[s]".

\subsection{Changing Conceptions of Engineering Work}

To explore how or why students' conceptions of the work of engineers might change over time, we highlight excerpts from interviews with four additional female participants (Girl 2, Girl 11, Girl 12, Girl 15). These are participants who drew girl engineers in both the pre- and post-drawings, but still advanced their knowledge of engineering work.

Girl 11 drew herself fixing a train in the pre-drawing and herself "helping the robots" in the post-drawing (Table 3). Notably, her written words describing engineering work bring into relief an ethic of care. She is "feeding robots and fixing robots when they are hurt." She elaborates in her interview.

Table 3. Pre/post drawings and student interviews provide evidence of conceptual change about the work of engineering.

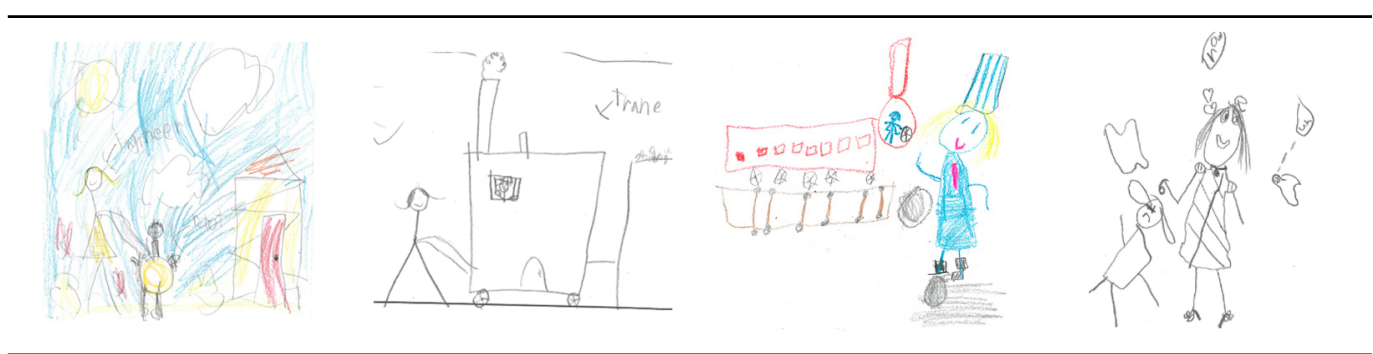

\section{Girl 2}

Pre-drawing: "That's a real engineer ... making a robot."

Post-drawing: "That was me when I was a little girl, I want to be an engineer when I grows up."

Why the change: "An engineer fixes things and if it doesn't work, she will try it again."

\section{Girl 11}

Pre-drawing: "She's helping make the train go."

Post-drawing: "She's helping robots ... like when they need more batteries and stuff."

Why the change: "Because I learned ... engineers, like, make stuff."

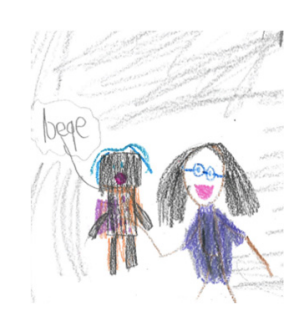

\section{Girl 12}

Pre-drawing: "She's fixing a robot, and her hair's kind of going out crazy because she's doing crazy things ... I've been watching some movies that had ... robots."

Post-drawing: "My engineer is fixing a robot. They can fix anything."

Why the change: "[I learned] that engineers make alarming systems ... and if someone feels the something then it goes off, like a fire alarm."

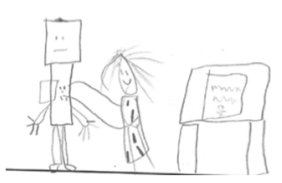

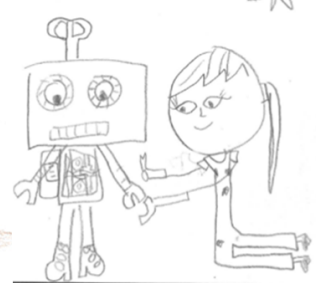

Girl 15

Pre-drawing: "An engineer ... fixes things and wants to make something new that no... other people, ever did ... This is adult."

Post-drawing: "This is the child making her own robot."

Why the change: "Because they can make something too ... and when they grow up, they can make more stuff out of their imagination."

Interviewer: Can you tell me about that person? What's that person doing?

Girl 11: She's helping make the train go.

Interviewer: What does she have to do to help them? Is the train broken?

Girl 11: The train lost a wheel. She would put the wheel back. 
Interviewer: Let's look at your drawing that you did afterwards. So, this is before, and this is the afterward. So, what can you tell me about this person?

Girl 11: She's helping robots, she's fixing robots. Like when they need more batteries and stuff.

Interviewer: Is this you again?

Girl 11: Yeah.

Interviewer: Okay ... What do you think made you change your mind about what engineers do?

Girl 11: I learned a little bit more about engineers, like [they] make stuff ...

Interviewer: Do you think you are an engineer? Yeah? Why?

Girl 11: Because I ... think about what to do, what do engineers do.

This participant explains that she came to understand engineers do more than fix stuff, they also "make stuff". Further, she describes her conception of engineering work as "helping" people or caring for robots "when they are hurt". This is consistent with other studies on students' identity work [34], in which conceptualizing engineering as a helping profession made the work more attractive to girls.

Girl 2 drew an engineer "making a robot" in the pre-drawing and "fixing a train" in the post-drawing (Table 3), but with a written response that indicates knowledge of engineering: "if it doesn't work, she will try it again". Her interview, however, clarified she actually holds a more sophisticated understanding of the work of engineers than the drawings alone let on. Interestingly, her interview responses also emphasized an ethic of care.

Girl 2: I want to be an engineer when I grows up.

Interviewer: You do? What made you want to be an engineer when you grew up?

Girl 2: ... Because I make things all my life ... with my dad.

Interviewer: With your dad, very good. What does your dad do?

Girl 2: He makes ... makes lots of things that helps people and that's how he gets money.

Interestingly, a third female participant also described her father as someone who "helps". However, even though she had a relatively advanced conception of engineering work, drawing a girl with a robot in both pre- and post-drawings (Table 3), she provided evidence of a kind of stereotype threat.

Interviewer: So, let's look at this picture that you drew. This is before you did the cookie-jar alarms. Can you tell me about this? What's this person doing here?

Girl 12: She is fixing a robot, and the robot's saying, "Beep." I was thinking that they could probably fix things, so she's fixing a robot, and her hair's kind of going out crazy because she's doing crazy things.

Why does she describe her father as helpful but the girl in her drawing as crazy? Her interview uncovered media as a possible source for her conceptions of engineers.

Girl 12: I've been watching movies that had androids and stuff that are kind of like robots ... There's a person named Anne and she's an engineer ... so I kind of learned a bit from them.

Based on this interview, the way the media portrays engineers and the work of engineers may be a significant factor in the development of girls' engineering identity.

Finally, Girl 15 also drew two delightful pictures of a girl "making robots" in both her pre- and post-drawings (Table 3). When probed in the interview, she explains her first drawing is an adult, and her second drawing is a child.

Interviewer: So, what can you tell me about the drawing you've done here?

Girl 15: I did an engineer that fixes things and wants to make something new that no one, other people, ever did.

Interviewer: Ah, okay ... can you tell me more about your engineer that you've drawn?

Girl 15: She made a robot that you can control from a remote.

Interviewer: And she's got that robot on the table?

Girl 15: Yeah. 
Interviewer: Very cool ... That's great. And then, after, what can you tell me about this drawing and what they're doing?

Girl 15: She's making a robot, like ... can childs make robot when they're little?

Interviewer: Oh yes, absolutely. Is that something you would be interested in learning how to do?

Girl 15: Yeah.

Interviewer: I really liked your drawing ... So is there any difference between these drawings?

Girl 15: This is adult, this is the child making her own robot.

Interviewer: Oh, in the first drawing it was an adult, and in the second drawing it's a child. Wow, that's really cool. Why is the first one an adult, and this one a child? What caused you to draw a child as an engineer?

Girl 15: Because they can make something too, that, like they've never, and when they grow up, they can make more stuff out of their imagination.

Interviewer: Did you draw a child as an engineer because you were thinking about being an engineer?

Girl 15: Yeah.

Interviewer: Very cool. What made you think about being an engineer?

Girl 15: To make something new and fix things.

Interviewer: You like to make new things and fix things, that's a great answer ... I think you might be an engineer.

Girl 15 understands that creativity is an important attribute of engineers because they have to "make something ... that ... they've never [seen] ... out of their imagination."

In summary, the new knowledge that supported conceptual change for the girls in this study was that engineers can "make lots of things that help people." Girls in this study framed engineering as care work, which suggests that an ethic of care could make engineering a more thinkable aspiration for girls. This framing may be necessary to help counteract media portrayals of engineers as people with "crazy hair" who do "crazy things." The girls in this study often spoke of the role of failure in engineering work: "If it doesn't work, she will try it again" and "if we messed up ... we figured it out." This suggests failure was viewed as necessary to improve a design solution, but also perhaps that the expectation of failure made the task less intimidating and opened up a safe space that encouraged girls to take risks. Importantly, the opportunity to make new things "out of their imagination" and be creative was welcomed by the girls in this study, perhaps leading to the realization that children (girls) possess this attribute and therefore can be engineers too, even "when they're little".

\subsection{Effectiveness of the Intervention}

To evaluate the effectiveness of the curricular intervention, we integrated the quantitative data from the Draw an Engineer Test and the qualitative interview data to categorize students' mental models of engineering along a continuum using a previously validated three-level rubric [21,61]. Students generally moved from a limited (Level 1) understanding of engineering as fixing/building to a basic (Level 2) understanding of engineering as designing (Figure 1). Some students also demonstrated a more advanced (Level 3) understanding of engineering as design for a purpose (i.e., to solve a problem that helps people). In the pre-test, the number of students at each level of understanding was 2 naive, 7 limited, 5 basic, and 1 advanced $(M=1.3, S D=0.8)$. Whereas in the posttest, the number of students at each level of understanding was 1 naive, 2 limited, 6 basic, and 6 advanced $(M=2.1$, $S D=0.9$ ). A pairwise Wilcoxon signed-rank test revealed that the median scores from the pre-test and post-test were significantly different, with students showing a more advanced understanding of the work of engineers following the two-week curricular intervention, $Z=-2.934, p=0.003$. The effect size was large according to Cohen's convention $(d=0.94)$. 


\section{Students' Conceptions of Engineering Work}

Pre-conceptions

Post-conceptions

8

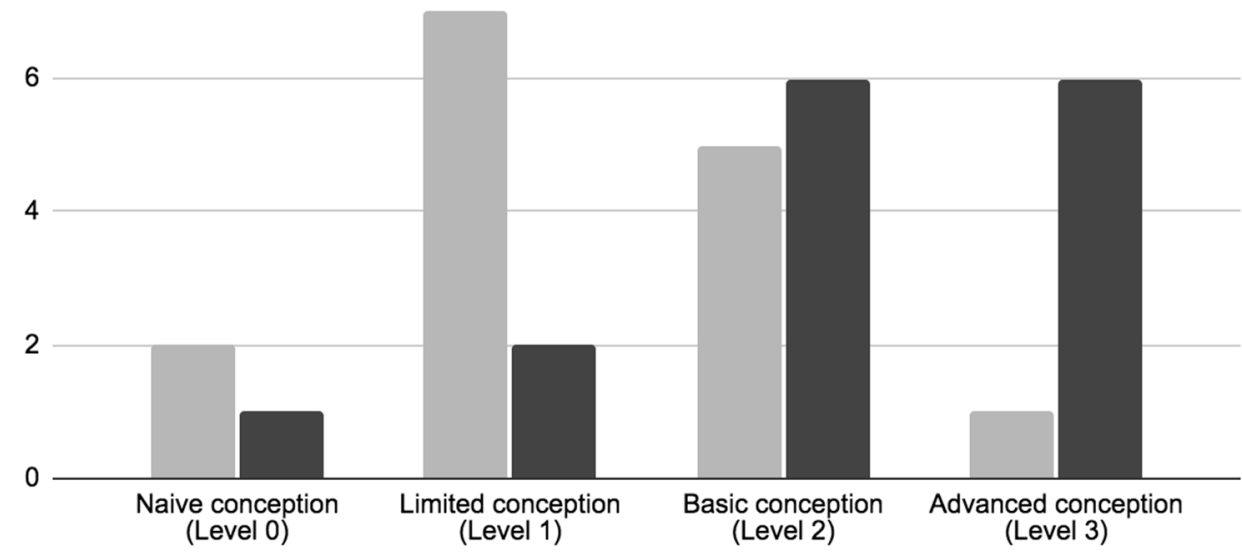

Figure 1. Students significantly advanced their understanding of engineering work following the curricular intervention regardless of gender $(p=0.003)$.

A Mann-Whitney $U$ test was conducted to compare the median score of boys versus girls. The differences were not significant on either the pre-test, $Z=1.562, p=0.059$, or post-test, $Z=1.331, p=0.092$, or after controlling for pretest scores by conducting a test on gain scores, $Z=0.521, p=0.302$. Thus, students' conceptual understanding of engineering work improved following the two-week curriculum intervention regardless of gender.

\subsection{Interest and Engineering Identity}

To address the question of whether a gender-neutral programming design task might differentially influence the interest and engineering identity of girls compared to boys, we analyzed data from a question posed in the interviews. We found that girls in this study were more likely than boys to identify as an engineer following the cookie-jar alarm design task. That is, more girls ( 6 of $8,75 \%$ ) than boys $(1$ of $7,14 \%$ ) responded in the affirmative when asked in the post-interview, "Do you think you are an engineer?" (Table 4). A Fisher's exact test was performed to examine the relation between gender and engineering identity. The relation between these variables was statistically significant $(p=0.041)$.

Table 4. Relationship between engineering identity and gender. Interaction between engineering identity and knowledge of engineering work (Spearman's rho).

\begin{tabular}{|c|c|c|c|c|}
\hline & \multicolumn{3}{|c|}{$\begin{array}{l}\text { Interview Survey Question } \\
\qquad n=15\end{array}$} & Significance Level \\
\hline Engineering Identity X Gender & $\begin{array}{l}\text { Male } \\
1 \text { of } 7 \\
(14 \%)\end{array}$ & $\begin{array}{c}\text { Female } \\
6 \text { of } 8 \\
(75 \%)\end{array}$ & $\begin{array}{c}\text { Total } \\
7 \text { of } 15 \\
(47 \%)\end{array}$ & $p=0.041^{*}$ \\
\hline $\begin{array}{c}\text { Engineering Identity X } \\
\text { Knowledge of Engineering }\end{array}$ & \multicolumn{3}{|c|}{$r_{S}=0.56$} & $p=0.030^{*}$ \\
\hline
\end{tabular}

When students were asked why they identify as an engineer, the most common reason was liking to make things ( 4 of 7,57\%), followed by an interest in figuring out how things work $(2$ of $7,29 \%)$. One female student $(14 \%)$ described wanting to be an engineer so she can help people. Students who did not identify themselves as an engineer cited that they did not like to build/fix ( 3 of $8,38 \%$ ) or make things (1 of $8,13 \%$ ), did not know how to build or were not good at building things ( 2 of $8,25 \%$ ), were not in charge of anything ( 1 of 
$8,13 \%$ ), or simply wanted to be something else when they grew up, such as a police officer or paleontologist.

Spearman's rho correlation coefficient was used to assess the relationship between students' engineering interest/identity and their knowledge of engineering work based on the three-level rubric (Table 4). The relationship between the two variables was significant, $r_{s}=0.56, p=0.030$, indicating that students who understand the work and attributes of engineers also show more interest in engineering.

\section{Discussion}

The purpose of this study was to better understand how students' (mis)conceptions of engineers and engineering work might disadvantage girls, and how a curriculum intervention might change these (mis)conceptions to better position girls as doers of STEM. The cookie-jar alarm curriculum [56] was intentionally designed to promote interest in engineering for all students, but especially for girls. We now discuss the results of this mixed-methods research study, including the changes observed in students' pre-/postdrawings of 'engineers at work' (QUAN), our interpretation of why students' conceptions changed based on data from student interviews (QUAL), and how the curricular intervention differentially influenced students' interest and engineering identity based on gender (MM).

We found that gendered conceptions of engineers were already present among firstgrade students in this study as the majority of children drew a male engineer in their pre-drawings $(67 \%)$, including almost half the girls. However, following the two-week curricular intervention, all girls drew female engineers. Girls (75\%) were more likely to include robots in their post-drawings of engineers than boys (29\%), providing evidence that the design task, which involved the coding of KIBO robots [32,33], may have been more impactful or meaningful to the girls in this study. Based on the evidence, we also believe that the (mis)conceptions of the boys in this study were more resistant to change than the girls', as they more often retained the idea of an engineer as a person who fixes trains/cars or builds houses/bridges rather than a person who designs for a purpose (i.e., to solve a problem that helps people).

Aspects of the curriculum design may explain why the girls in this study experienced a greater change in their conceptions of engineers than boys. First, we think the KIBO robots made engineering fun and accessible for all students, but especially the girls. We chose the cookie-jar alarm design task because we considered it to be gender-neutral, unlike many other engineering curricula [15-17] in which students design a vehicle (e.g., car, rocket) or large structure (e.g., bridge, tower), often thought of as "boy stuff". Second, the cookie-jar alarm engineering curriculum emphasized care and collaboration rather than competition to solve a problem. A storybook narrative provided context and introduced the problem to be solved through engineering [57], motivating students to help the main character. Framing engineering as solving problems to help people has been shown to promote girls' participation in engineering [33-35].

The qualitative data from student interviews support our interpretations. When girls were asked about what caused them to change their thinking about engineers, they described learning that engineers "make lots of things that help people" and "there's a lot of kinds of engineers." Thus, girls in this study readily took up engineering as care work, but also recognized the need to expand their thinking (dispel stereotypes?) about who can be an engineer. Interestingly, a male participant described that his thinking changed because he realized engineers can work on "small thing[s]" not just "bigger thing[s]". Knowing that engineers can work on things other than vehicles and large structures, including small cookie-jar alarms, seemed to open up new possibilities for the kinds of work that engineers can engage in, and therefore, who can be an engineer. Coding and programming in particular may be an avenue to position girls as doers of STEM.

Finally, the most compelling finding of our study was that the girls $(75 \%)$ showed more interest in engineering than the boys (14\%) following the cookie-jar alarm design 
task $(p=0.041)$. Specifically, more girls than boys responded in the affirmative when asked, "Do you think you are an engineer?" This suggests the curriculum supported the girls in this study, but not so much the boys, in developing an engineering identity. Notably, all students' conceptual understanding of engineering work improved following the two-week curricular intervention, regardless of gender. Students in this study generally advanced from a limited (Level 1) understanding to a basic (Level 2) understanding of engineering. Some students (40\%) even developed an advanced (Level 3) understanding, conceptualizing engineering as design for a purpose (i.e., to solve a problem that helps people). This difference was statistically significant $(p=0.003)$ and the effect size was large $(\mathrm{d}=0.94)$.

The results of the study provide preliminary evidence that certain understandings can influence or change students' (gendered) conceptions of engineers, rendering engineering a more thinkable aspiration for girls $[62,63]$. We argue that more attention should be given to the complex question of which engineering curricula work, for whom, in what context, how they work, and how they can be improved. An emphasis on the development of "genderresponsive" engineering curricula could be a means to promote equity in STEM education and perhaps lead to increased participation of women in the engineering profession.

\section{Limitations and Future Research}

Due to the exploratory nature of the study, a limitation is the small sample size. We hope to extend the cookie-jar alarm curriculum using KIBO robots to a larger number of students in a future study. Also, we did not conduct pre-interviews with students to assess their interest in engineering prior to participation in this study. However, this was intentional, as a previously documented limitation of working with young children is that they do not yet have a sufficient understanding of engineering to respond meaningfully to questions that use the term [25]. Pre-interviews are thus unproductive. Instead, researchers recommend that K-2 students participate in an engineering design task, then reflect back, comparing their interest in engineering before and after the curricular intervention. In addition, it may not be developmentally appropriate to ask young children to answer questions about their interest in a future career. We circumvented this challenge by asking students the question, "Do you think you are an engineer (now)? Why or why not?" Finally, the first author alone carried out the coding of the qualitative interview data. Having multiple coders could have brought different perspectives to the data and enriched the interpretation. More research is needed to uncover how specific design tasks influence students' interest and engineering identity based on gender for the purpose of promoting equity in engineering education.

\section{Conclusions}

In summary, a mixed analysis of data from students' pre-/post-drawings and interviews supports a grounded theory about how or why students might respond differently to the same engineering curriculum based on gender. We argue that, to promote equity in engineering education, students' gendered conceptions of engineers must be made visible to themselves and others. In addition, students must be introduced to a variety of work in which engineers may engage. Coding and programming in particular may be an avenue to position girls as doers of STEM. Attributes of engineers [10] can be explicitly taught; creativity, for example, is one that many girls envision themselves as possessing. Finally, students must work collaboratively to solve problems that help people. Framing engineering as care work rather than competition is key [33-35]. Based on these findings, we recommend that to promote equity in engineering education "gender-responsive" curricula are essential to maintain girls' interest in engineering over time.

Author Contributions: Conceptualization, A.M., K.H.L. and C.T.-G.; methodology, A.M., K.H.L. and C.T.-G.; formal analysis, A.M.; investigation, K.H.L. and C.T.-G.; data curation, K.H.L.; original draft preparation, A.M.; writing-review and editing, A.M., K.H.L. and C.T.-G.; supervision, K.H.L.; project administration, K.H.L. All authors have read and agreed to the published version of the manuscript. 
Funding: This research received no external funding.

Institutional Review Board Statement: The study was conducted in accordance with the Declaration of Helsinki, and approved by the Institutional Review Board of Utah State University (protocol \#10227 and 04/29/2019) for studies involving humans.

Informed Consent Statement: Informed consent was obtained from all subjects involved in the study.

Data Availability Statement: Not applicable.

Conflicts of Interest: The authors declare no conflict of interest.

\section{Appendix A. Interview Protocol}

1. [Looking at the first drawing] What can you tell me about this drawing?

a. What is the engineer doing?

b. How did you know or learn that?

c. [If the gender is not mentioned by pronouns, then ask: Is the engineer a boy or a girl?]

2. [Looking at your second drawing] What can you tell me about this drawing?

a. What is the engineer doing now?

b. [If the gender is not mentioned by pronouns, then ask: Is the engineer a boy or a girl?]

3. [Looking at your two drawings side-by-side] How are these drawings different?

a. What made you change your mind about what engineers do?

4. Do you think you are an engineer? Why, or why not?

\section{References}

1. Moore, T.J.; Glancy, A.W.; Tank, K.M.; Kersten, J.A.; Smith, K.A.; Stohlmann, M.S. A framework for quality K-12 engineering education: Research and development. J. Pre-Coll. Eng. Educ. Res. J-PEER 2014, 4, 2. [CrossRef]

2. Pleasants, J.; Olson, J.K. What is engineering? Elaborating the nature of engineering for K-12 education. Sci. Educ. 2019, 103, 145-166. [CrossRef]

3. Moore, T.J.; Tank, K.M.; Glancy, A.W.; Kersten, J.A. NGSS and the landscape of engineering in K-12 state science standards. J. Res. Sci. Teach. 2015, 52, 296-318. [CrossRef]

4. National Research Council (NRC). STEM Integration in K-12 Education: Status, Prospects, and an Agenda for Research; The National Academies Press: Washington, DC, USA, 2014. [CrossRef]

5. Roehrig, G.H.; Moore, T.J.; Wang, H.-H.; Park, M.S. Is adding the E enough? Investigating the impact of K-12 engineering standards on the implementation of STEM integration. Sch. Sci. Math. 2012, 112, 31-44. [CrossRef]

6. Ladson-Billings, G. Toward a theory of culturally relevant pedagogy. Am. Educ. Res. J. 1995, 32, 465-491. [CrossRef]

7. National Science Foundation (NSF). Women, Minorities, and Persons with Disabilities in Science and Engineering: 2015; Special Report NSF 15-311; National Center for Science and Engineering Statistics: Arlington, VA, USA, 2015. Available online: http:/ / www.nsf.gov / statistics/wmpd/ (accessed on 16 December 2021).

8. Moote, J.; Archer, L.; DeWitt, J.; MacLeod, E. Comparing students' engineering and science aspirations from age 10 to 16: Investigating the role of gender, ethnicity, cultural capital, and attitudinal factors. J. Eng. Educ. 2020, 109, 34-51. [CrossRef]

9. Ozogul, G.; Miller, C.F.; Reisslein, M. Latinx and Caucasian elementary school children's knowledge of and interest in engineering activities. J. Pre-Coll. Eng. Educ. Res. 2017, 7, 15-26. [CrossRef]

10. Capobianco, B.M.; Diefes-Dux, H.A.; Mena, I.; Weller, J. What is an engineer? Implications of elementary school student conceptions for engineering education. J. Eng. Educ. 2011, 100, 304-328. [CrossRef]

11. Weber, N.; Duncan, D.; Dyehouse, M.; Strobel, J.; Diefes-Dux, H.A. The development of a systematic coding system for elementary students' drawings of engineers. J. Pre-Coll. Eng. Educ. Res. J-PEER 2011, 1, 6. [CrossRef]

12. Fralick, B.; Kearn, J.; Thompson, S.; Lyons, J. How middle schoolers draw engineers and scientists. J. Sci. Educ. Technol. 2009, 18, 60-73. [CrossRef]

13. Karatas, F.; Micklos, A.; Bodner, G. Sixth-grade students' views of the nature of engineering and images of engineers. J. Sci. Educ. Technol. 2011, 20, 123-135. [CrossRef]

14. Cejka, E.; Rogers, C.; Portsmore, M. Kindergarten robotics: Using robotics to motivate math, science, and engineering literacy in elementary school. Int. J. Eng. Educ. 2006, 22, 711-722.

15. Pekmez, E. Primary school students' views about science, technology and engineering. Educ. Res. Rev. 2018, 13, 81-91.

16. Wendell, K.B.; Andrews, C.J.; Paugh, P. Supporting knowledge construction in elementary engineering design. Sci. Educ. 2019, 103, 952-978. [CrossRef] 
17. Cunningham, C.M.; Carlsen, W.S. Teaching engineering practices. J. Sci. Teach. Educ. 2014, 25, 197-210. [CrossRef]

18. Cunningham, C.M.; Kelly, G.Y.J. Epistemic practices of engineering for education. Sci. Educ. 2017, 101, 486-505. [CrossRef]

19. Knight, M.; Cunningham, C. Draw an Engineer Test (DAET): Development of a tool to investigate students' ideas about engineers and engineering. In Proceedings of the 2004 American Society for Engineering Education Annual Conference \& Exposition, Salt Lake City, UT, USA, 20-23 June 2004.

20. Chambers, D. Stereotypic images of the scientist: The draw-a-scientist test. Sci. Educ. 1983, 67, 255-265. [CrossRef]

21. Thomas, J.; Hawley, L.R.; DeVore-Wedding, B. Expanded understanding of student conceptions of engineers: Validation of the modified draw-an-engineer test (mDAET) scoring rubric. Sch. Sci. Math. 2020, 120, 391-401. [CrossRef]

22. Hammack, R.; Utley, J.; Ivey, T.; High, K. Elementary teachers' mental images of engineers at work. J. Pre-Coll. Eng. Educ. Res. 2020, 10, 3. [CrossRef]

23. Capobianco, B.M.; French, B.; Diefes-Dux, H. Engineering identity development among pre-adolescent learners. J. Eng. Educ. 2012, 101, 698-716. [CrossRef]

24. Capobianco, B.M.; Deemer, E.D.; Lin, C. Analyzing predictors of children's formative engineering identity development. Int. J. Eng. Educ. 2017, 33, 44-54.

25. Lachapelle, C.P.; Brennan, R.T. An instrument for examining elementary engineering student interests and attitudes. Int. J. Educ. Math. Sci. Technol. 2018, 6, 221-240. [CrossRef]

26. Brophy, S.; Klein, S.; Portsmore, M.; Rogers, C. Advancing engineering education in P-12 classrooms. J. Eng. Educ. 2008, $97,369$. [CrossRef]

27. Yoon, S.Y.; Dyehouse, M.; Lucietto, A.M.; Diefes-Dux, H.A.; Capobianco, B.M. The effects of integrated science, technology, and engineering education on elementary students' knowledge and identity development. Sch. Sci. Math. 2011, 114, 380-391. [CrossRef]

28. Capobianco, B.M.; Yu, J.H.; French, B.F. Effects of engineering design-based science on elementary school science students' engineering identity development across gender and grade. Res. Sci. Educ. 2015, 45, 275-292. [CrossRef]

29. Cunningham, C.M.; Lachapelle, C.P.; Brennan, R.T.; Kelly, G.J.; Tunis, C.S.A.; Gentry, C.A. The impact of engineering curriculum design principles on elementary students' engineering and science learning. J. Res. Sci. Teach. 2020, 57, 423-453. [CrossRef]

30. Kelly, G.J.; Cunningham, C.M. Epistemic tools in engineering design for K-12 education. Sci. Educ. 2019, 103, 1080-1111. [CrossRef]

31. Hertel, J.D.; Cunningham, C.M.; Kelly, G.J. The roles of engineering notebooks in shaping elementary engineering student discourse and practice. Int. J. Sci. Educ. 2017, 39, 1194-1217. [CrossRef]

32. Elkin, M.; Sullivan, A.; Bers, M.U. Programming with the KIBO robotics kit in preschool classrooms. Comput. Sch. 2016, 33, 169-186. [CrossRef]

33. Sullivan, A.; Bers, M.U. Investigating the use of robotics to increase girls' interest in engineering during early elementary school. Int. J. Technol. Des. Educ. 2019, 29, 1033-1051. [CrossRef]

34. Capobianco, B.M.; Yu, J.H. Using the construct of care to frame engineering as a caring profession toward promoting young girls' participation. J. Women Minorities Sci. Eng. 2014, 20, 21-33. [CrossRef]

35. Gunckel, K.L.; Tolbert, S. The imperative to move toward a dimension of care in engineering education. J. Res. Sci. Teach. 2018, 55, 938-961. [CrossRef]

36. Creswell, J.W.; Plano Clark, V.L.; Gutman, M.L.; Hanson, W.E. Advanced mixed methods research designs. In Handbook of Mixed Methods in Social and Behavioral Research; Tashakkori, A., Teddlie, C., Eds.; SAGE: Thousand Oaks, CA, USA, 2003 ; pp. 209-240. [CrossRef]

37. Mertens, D.M. Transformative paradigm: Mixed methods and social justice. J. Mix. Methods Res. 2007, 1, 212-225. [CrossRef]

38. Mertens, D.M. Transformative mixed methods: Addressing inequities. Am. Behav. Sci. 2012, 56, 802-813. [CrossRef]

39. Sweetman, D.; Badiee, M.; Creswell, J.W. Use of the transformative framework in mixed methods studies. Qual. Inq. 2010, 16, 441-454. [CrossRef]

40. Johnson, R.B.; McGowan, M.W.; Turner, L.A. Grounded theory in practice: Is it inherently a mixed method? Res. Sch. 2010, 17, 65-78.

41. Creamer, E.G. Enlarging the conceptualization of mixed method approaches to grounded theory with intervention research. Am. Behav. Sci. 2018, 62, 919-934. [CrossRef]

42. Guetterman, T.C.; Babchuk, W.A.; Howell Smith, M.C.; Stevens, J. Contemporary approaches to mixed methods-grounded theory research: A field-based analysis. J. Mix. Methods Res. 2019, 13, 179-195. [CrossRef]

43. Stacey, J. Untangling feminist theory. In Introducing Women's Studies; Richardson, D., Robinson, V., Eds.; Palgrave Macmillan: London, UK, 1993; pp. 44-73. [CrossRef]

44. Beauvoir, S. The Second Sex; Vintage Books: New York, NY, USA, 1949.

45. Hooks, B. Feminist Theory: From Margin to Center; South End Press: Boston, MA, USA, 1984.

46. Hooks, B. Teaching to Transgress: Education as the Practice of Freedom; Routledge: New York, NY, USA, 1994.

47. Butler, J.P. Gender Trouble: Feminism and the Subversion of Identity; Routledge: London, UK, 1990.

48. Avraamidou, L. Science identity as a landscape of becoming: Rethinking recognition and emotions through an intersectionality lens. Cult. Stud. Sci. Educ. 2020, 15, 323-345. [CrossRef] 
49. Tisdell, E. Feminist epistemology. In The Sage Encyclopedia of Qualitative Research Methods; Given, L., Ed.; Sage Publications: Los Angeles, CA, USA, 2008; Volume 1, pp. 331-335.

50. Brotman, J.S.; Moore, F.M. Girls and science: A review of four themes in the science education literature. J. Res. Sci. Teach. 2008, 45, 971-1002. [CrossRef]

51. Mansfield, K.C.; Welton, A.D.; Grogan, M. "Truth or consequences": A feminist critical policy analysis of the STEM crisis. Int. J. Qual. Stud. Educ. 2014, 27, 1155-1182. [CrossRef]

52. Keller, E.F. Feminism and science. Signs J. Women Cult. Soc. 1982, 7, 589-602. [CrossRef]

53. Haraway, D.J. Situated knowledges: The science question in feminism and the privilege of perspective. Fem. Stud. 1988, 14, 575-599. [CrossRef]

54. Harding, S. Rethinking standpoint epistemology: What is "strong objectivity"? In Feminist Epistemologies; Alcoff, L., Potter, E., Eds.; Routledge: New York, NY, USA, 1993; pp. 49-82.

55. Calabrese Barton, A.; Tan, E. Designing for rightful presence in STEM: The role of making present practices. J. Learn. Sci. 2019, 28, 616-658. [CrossRef]

56. Lott, K.; Urbanek-Carney, S.; Mitchell, A. Cookie jar alarms: Early childhood engineering with robotics. Sci. Child. 2019, 57, 66-72. [CrossRef]

57. Bers, M.U. Coding as another language: A pedagogical approach for teaching computer science in early childhood. J. Comput. Educ. 2019, 6, 499-528. [CrossRef]

58. Kelley, T.R.; Sung, E. Sketching by design: Teaching sketching to young learners. Int. J. Technol. Des. Educ. 2017, 27, 363-386. [CrossRef]

59. Peterman, K.; Daugherty, J.L.; Custer, R.L.; Ross, J.M. Analysing the integration of engineering in science lessons with the Engineering-Infused Lesson Rubric. Int. J. Sci. Educ. 2017, 39, 1913-1931. [CrossRef]

60. Douglas, K.A.; Moore, T.J.; Johnston, A.C.; Merzdorf, H.E. Informed designers? Students' reflections on their engineering design process. Int. J. Educ. Math. Sci. Technol. 2018, 6, 443-459. [CrossRef]

61. Thomas, J.; Colston, N.M.; Ley, T.; DeVore-Wedding, B.; Hawley, L.R.; Utley, J.; Ivey, T. Fundamental research: Developing a rubric to assess children's drawings of an engineer at work. In Proceedings of the ASEE Annual Conference and Exposition, New Orleans, LA, USA, 26 June-28 August 2016. [CrossRef]

62. Archer, L.; Dewitt, J.; Osborne, J.; Dillon, J.; Willis, B.; Wong, B. "Balancing acts": Elementary school girls' negotiations of femininity, achievement, and science. Sci. Educ. 2012, 96, 967-989. [CrossRef]

63. Ing, M.; Aschbacher, P.R.; Tsai, S.M. Gender differences in the consistency of middle school students' interest in engineering and science careers. J. Pre-Coll. Eng. Educ. Res. J-PEER 2014, 4, 2. [CrossRef] 